\title{
CALCIFICAÇÕES DO ENXERTO HEPÁTICO EM UM CASO DE REJEIÇÃO AGUDA
}

\author{
Liver graft calcifications in a case of acute rejection
}

Mariana Santos Leite Pessoa, Marina Seixas Studart e Neves, Ivelise Regina Canuto Brasil, Gabriela Maia Coelho, José Telmo Valença Júnior, Jorge Luis Bezerra Holanda

\section{RESUMO}

Os exames de imagem são amplamente utilizados na avaliação de complicações após transplante hepático. Entretanto, os relatos na literatura de calcificações do enxerto são raros e inespecíficos, podendo remeter mais frequentemente a dano por injúria-reperfusão, isquemia ou até mesmo rejeição. Relatamos o caso de um paciente do sexo masculino, quarenta e oito anos de idade, diabético e hipertenso, internado para transplante hepático por cirrose criptogênica e esquistossomose. Cerca de vinte dias após o transplante apresentou alterações de parâmetros clínicos e bioquímicos com elevação de enzimas canaliculares e hiperbilirrubinemia à custa de bilirrubina direta, com exames de imagens demonstrando calcificações hepáticas distróficas pericapsulares, bem como estenose da artéria hepática, sendo realizada angioplastia sem colocação de stent. Biópsia por punção do enxerto hepático evidenciou rejeição celular aguda. São necessários novos estudos com maior descrição e caracterização das calcificações hepáticas pós-transplante, bem como compreensão dos mecanismos que proporcionam estas calcificações, visto que a detecção precoce de complicações pós-transplante ajudará a diminuir as taxas de morbidade e permite a recuperação do enxerto em casos selecionados.

Descritores: Transplante Hepático; Diagnóstico por Imagem; Rejeição de Enxerto; Isquemia.

\section{Instituição:}

Departamento de Radiologia do Hospital Geral de Fortaleza Ceará, Brasill.

\section{Correspondência:}

Mariana Santos Leite Pessoa

Rua Ávila Goulart, 900 - Papicu, CEP 60150-160, Fortaleza/CE - Brasil (88) 99639-4015.

marianaleite170@gmail.com

\section{INTRODUÇÃO}

O transplante hepático constitui o principal tratamento para a doença hepática terminal. ${ }^{1,2}$ No Brasil, segundo dados da Associação Brasileira de Transplante de Órgãos, de janeiro a dezembro de 2019, foram realizados cerca de 2245 transplantes hepáticos. ${ }^{3}$

O exame de imagem do paciente transplantado é bastante útil na avaliação das complicações; ${ }^{2}$ deste modo, múltiplos fatores devem ser levados em consideração pelo radiologista, visto que a cirurgia é complexa e requer anastomose do ducto biliar, veia cava inferior, artéria hepática e veia porta. ${ }^{1}$

$\mathrm{Na}$ avaliação da imagem pós-transplante, as complicações são amplamente classificadas em vascular, biliar e outras complicações. ${ }^{1}$ A trombose da artéria hepática é a complicação vascular mais frequente, e está frequentemente associada à falha do enxerto, sendo a ultrassonografia com doppler e angiotomografia úteis na sua avaliação. ${ }^{1}$ 
São escassos os relatos na literatura de casos de transplante hepático associados a calcificações nos exames de imagem, o que nos faz acreditar que esses casos sejam subnotificados. ${ }^{4,5}$ As calcificações são divididas em: distrófica (envolvendo células não viáveis ou danificadas do parênquima) ou metastática (relacionada à hipercalcemia sistêmica), sendo a primeira um achado mais comum no tecido infartado. ${ }^{6-8}$

O processo de obtenção de órgãos para transplante de fígado requer perfusão a frio, armazenamento hipotérmico para transporte, isquemia quente in situ e reperfusão a quente do aloenxerto. ${ }^{7}$ Esses eventos determinam estresse oxidativo nos hepatócitos e podem levar à lesão induzida por isquemia / reperfusão (RI).7 Embora mudanças nas soluções de preservação tenham melhorado a sobrevivência do enxerto, o dano por isquemia-reperfusão ainda é uma das principais causas de disfunção primária do enxerto. ${ }^{7}$

Estudos recentes sugerem uma possível ligação entre calcificação e lesão de isquemia-reperfusão após transplante hepático, mas esses eventos moleculares são pouco conhecidos. ${ }^{5-7}$ Há evidências de que eventos apoptóticos e necróticos podem ocorrer, e ocasionalmente, resultar em disfunção primária do enxerto, podendo levar ao desenvolvimento de calcificações na sua forma mais grave. ${ }^{5}$ Tzimas et al relataram dois casos em que lesão de injúria e reperfusão correlacionou-se com o desenvolvimento de calcificação hepática e disfunção do enxerto, um deles evidenciado apenas no estudo microscópico. ${ }^{5}$

A macrocalcificação hepática após o transplante pode ser, ainda, consequência de uma resposta generalizada ao dano, envolvendo diferenciação de miofibroblastos ativados em osteoblastos, bem como a presença de acúmulo intracelular de depósitos de hidroxiapatita nos hepatócitos, o que pode estar associada à lesão induzida por isquemia/reperfusão supracitada. ${ }^{6}$

Jeng et al descreveram um caso raro, em que foi observada calcificação geográfica no enxerto hepático devido a torção da veia hepática esquerda. ${ }^{4}$

Dupuy et al relataram dois casos de infarto hepático cursando com calcificações nos exames de imagem, o primeiro aparecendo com cerca de duas semanas e o segundo, em um mês. ${ }^{2} \mathrm{O}$ exame histológico do primeiro paciente mostrou áreas de infarto, presumivelmente por embolia séptica e leve rejeição celular. ${ }^{2} \mathrm{O}$ fígado no segundo paciente apresentou alterações isquêmicas, a maioria com necrose coagulativa franca e cálcio extracelular. $^{2}$

\section{RELATO DE CASO}

Paciente do sexo masculino, quarenta e oito anos de idade, internado para transplante hepático por cirrose criptogênica e esquistossomose (priorizado por ascite refratária). Antecedentes de diabetes mellitus tipo 2 (DM 2), hipertensão arterial e anemia severa. Sorologias para hepatites B e C, toxoplasmose, doença de Chagas, HIV e VDRL negativos, sorologia para citomegalovírus IgG reagente.

Realizado transplante hepático com fígado de doador falecido, sendo a causa mortis hemorragia subaracnoide, com sorologias positivas para toxoplasmose e citomegalovírus.

Transoperatório tecnicamente difícil, devido à trombose extensa da veia porta. Tempo de isquemia fria de quatro horas e tempo de isquemia quente de 52 minutos.

O paciente foi admitido na Unidade Pós-operatória de Alta Complexidade (UPAC), no pós-operatório imediato, estável clinicamente, sem sedação, Glasgow 15, em uso de noradrenalina em desmame, iniciado tacrolimus. $O$ paciente apresentava parâmetros vitais sem alterações significativas exceto por hiperglicemia, que foi controlada após medicações, e os drenos abdominais apresentavam secreção sero-hemática. Os exames laboratoriais evidenciavam hiperbilirrubinemia à custa de bilirrubina direta, com bilirrubina total (BT): $2,87 \mathrm{mg} / \mathrm{dL}$, bilirrubina direta (BD): $2,04 \mathrm{mg} / \mathrm{dL}$, elevação de transaminases (transaminase glutâmico pirúvica: $2188 \mathrm{U} / \mathrm{L}$; transaminase glutâmico oxalacética: 2099 U/L), INR: 2,01.

Ultrassonografia com doppler do enxerto hepático realizado no segundo dia pós-operatório evidenciou fígado transplantado de aspecto normal, com índice de resistência da artéria hepática no limite superior da normalidade, pequena quantidade de líquido livre na cavidade abdominal, bem como esplenomegalia homogênea, com ectasia da veia esplênica e colaterais calibrosas no mesogástrio.

A partir do terceiro dia do pós-operatório, o paciente iniciou dor abdominal, vômitos e retração da diurese $(400 \mathrm{ml} / 24 \mathrm{~h})$, que persistiram apesar do manejo clínico, sendo orientado pela nefrologia iniciar hemodiálise cerca de oito dias após o transplante, e que permaneceu sendo realizada três vezes na semana durante quatorze dias, período em que houve melhora da função renal.

Cerca de uma semana após o transplante, o paciente passou a apresentar aumento da secreção amarelada, de aspecto bilioso pelo dreno sub-hepático. Realizada derivação biliodigestiva (coledocojejunoanastomose) no nono dia pós-transplante hepático devido à fístula biliar bloqueada no colédoco nativo, com enterectomia e enteroanastomose por conta de mesentério curto. 
Mariana Santos Leite Pessoa, Marina Seixas Studart e Neves, Ivelise Regina Canuto Brasil, Gabriela Maia Coelho, José Telmo Valença Júnior, Jorge Luis Bezerra Holanda

Por volta do vigésimo dia pós-operatório, o paciente passou a apresentar picos febris com calafrios, bem como aumento de bilirrubina (bilirrubina total: $18,21 \mathrm{mg} /$ $\mathrm{dL}$; bilirrubina direta: $14,05 \mathrm{mg} / \mathrm{dL}$; bilirrubina indireta: $4,16 \mathrm{mg} / \mathrm{dL}$ ) e enzimas canaliculares (fosfatase alcalina: $1107 \mathrm{U} / \mathrm{dL}$ e gama glutamiltransferase: $423 \mathrm{U} / \mathrm{L}$ ), que tiveram piora crescente nas semanas seguintes. Nesse período, foi realizada ultrassonografia abdominal que mostrou imagens ecogênicas amorfas no parênquima hepático, algumas determinando sombra acústica, podendo corresponder a calcificações (Fig. 1).

Figura 1: Imagens de ultrassonografia em planos coronal e sagital do no lobo direito evidenciando imagens ecogênicas amorfas no parênquima hepático (setas), algumas com tênue sombra acústica (seta descontinua).

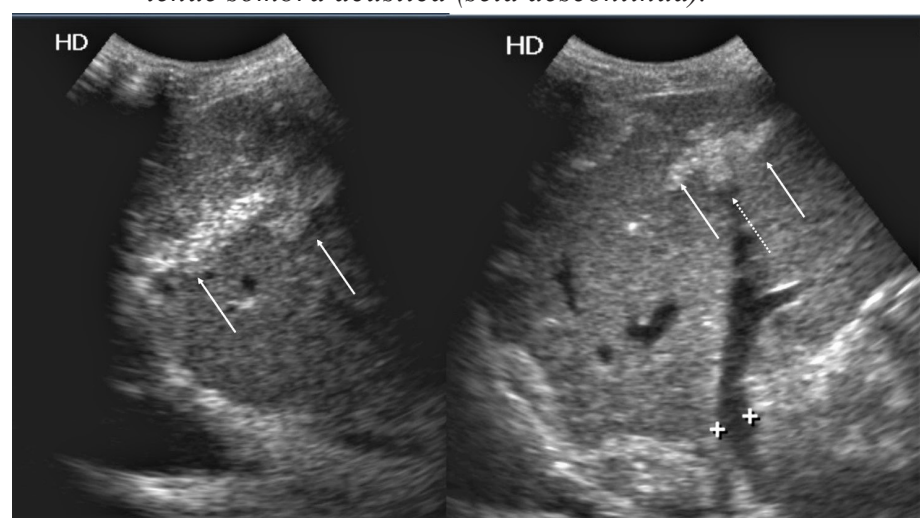

Tomografia computadorizada com contraste realizada, em seguida, evidenciou fígado transplantado de dimensões normais, exibindo extensos focos de calcificação amorfos, de predomínio subcapsular em ambos os lobos, de aspecto distrófico, (Fig. 2,3), achados que, embora inespecíficos, poderiam estar associados a sequelas de isquemia e/ou rejeição. Além disso, observou-se ectasia da veia porta $(1,8 \mathrm{~cm})$ e grande quantidade de líquido livre na cavidade abdominopélvica, bem como esplenomegalia homogênea.

Figura 2: Reconstrução MIP coronal com espessura de $6 \mathrm{~cm}$, retirando os arcos costais para melhor evidenciar o acometimento das calcificações no parênquima hepático.

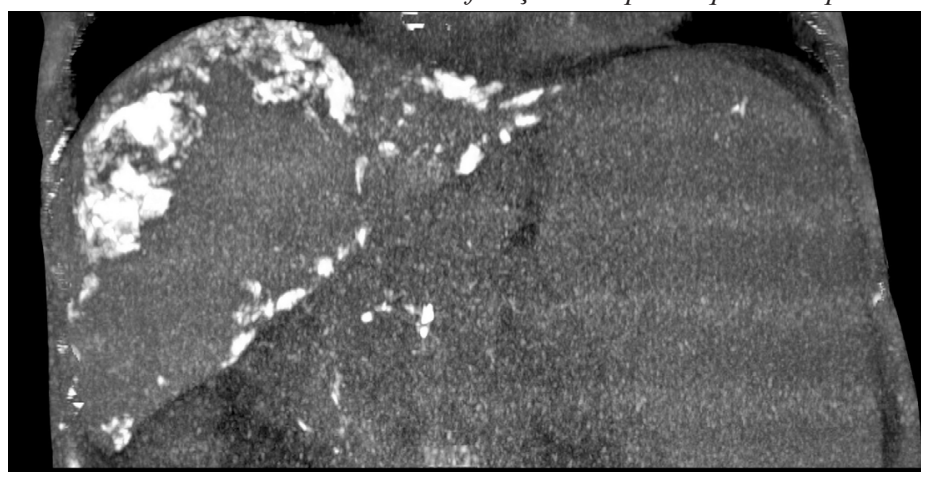

Figura 3: Imagem de tomografia do abdome em fase sem contraste exibindo calcificações amorfas hepáticas nos lobos esquerdo e de forma mais exuberante no direito (setas).

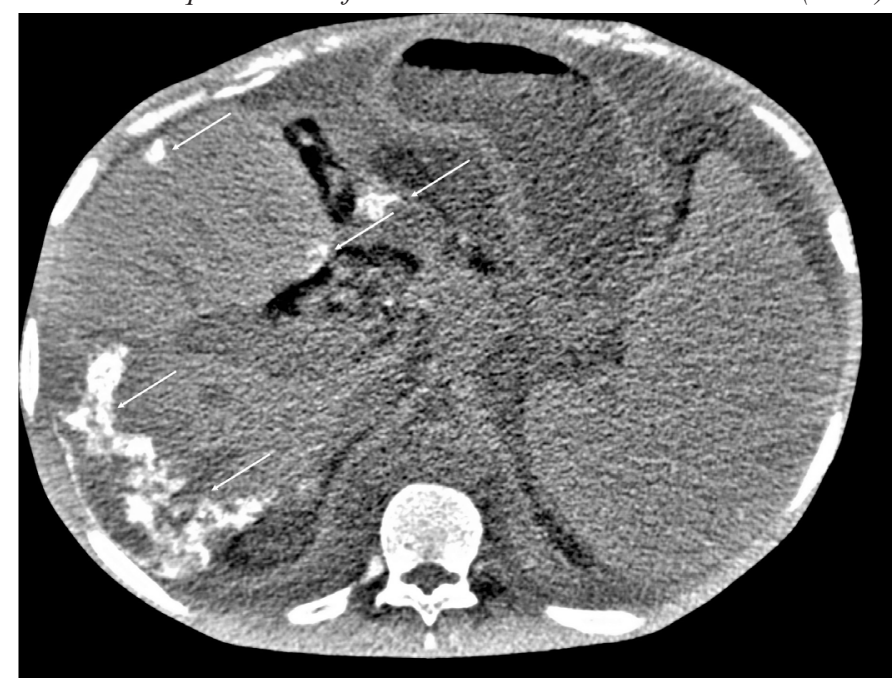

É importante ressaltar que o doador não apresentava evidência de deposição de cristal ou doença de armazenamento e o receptor não apresentava qualquer evidência de problemas no metabolismo do cálcio.

Orientado pela equipe de radiologia, a complementação com angiotomografia computadorizada do abdome e da pelve foi feita na semana seguinte, ao completar um mês do transplante hepático. O exame evidenciou tronco comum à artéria mesentérica superior e ao tronco celíaco, pérvio, sem falhas de enchimento. Observouse ainda artéria hepática comum com diâmetro e contornos preservados nos seus segmentos proximal e médio, a partir do qual exibia contornos irregulares e diâmetro reduzido, provavelmente, correspondendo à artéria hepática do doador, estendendo-se até as proximidades do hilo hepático, onde bifurcava-se em artérias hepáticas direita e esquerda, ambas mantendo contornos irregulares e diâmetros afilados, com estreitamentos focais (Fig. 4). Foram observadas, ainda, dilatação e tortuosidade do trajeto da veia esplênica e da topografia da confluência esplenomesentérica,notandose a presença de vaso anômalo estendendo-se da confluência esplenomesentérica, superiormente, para a região periesofagiana, com exuberantes varizes nessa topografia, com a veia porta do doador anastomosada neste vaso anômalo, com leve ectasia do seu diâmetro, sem falhas de enchimento. Colangiorressonância magnética realizada no período não evidenciou dilatações de vias biliares intra ou extra-hepáticas.

$\mathrm{Na}$ mesma semana foi realizada arteriografia com angioplastia da artéria hepática sem colocação de stent. Cerca de duas semanas depois, repetiu-se a arteriografia, com flebografia e biópsia, evidenciando artéria hepática com bom fluxo. 
Figura 4: Reconstrução MIP coronal de exame de angioTC de abdome demostrando afilamentos e irregularidade de contornos da artéria hepática do receptor (seta) e de seus ramos direito e esquerdo (setas descontínuas) $e$ artéria do receptor (seta longa) com calibre normal.

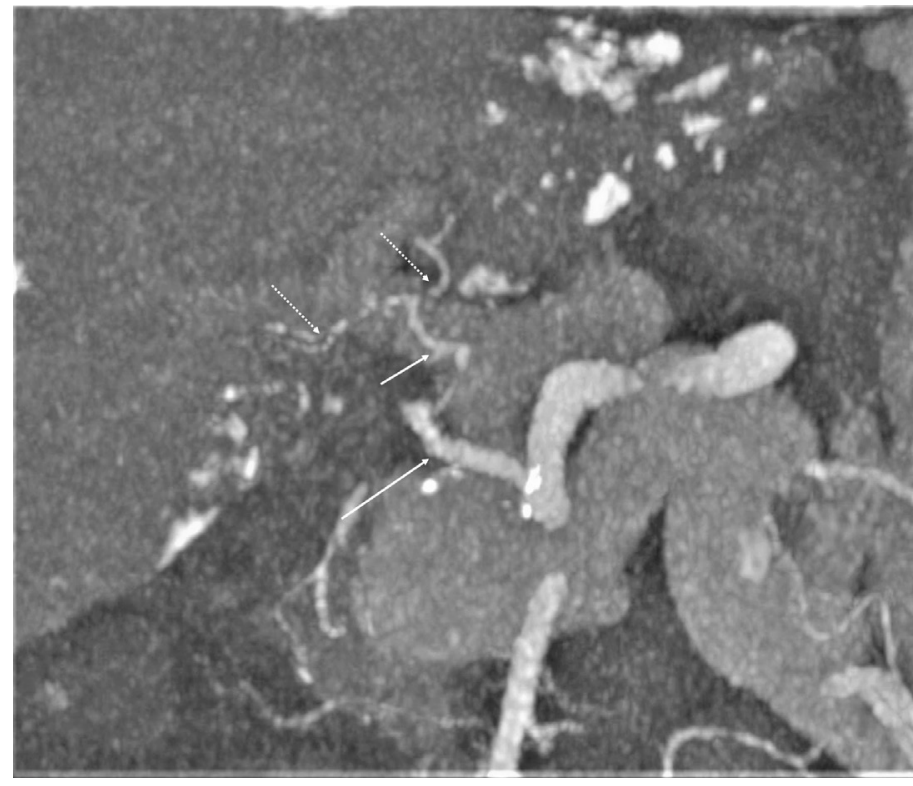

O laudo histopatológico da biópsia realizada cerca de um mês e meio após o transplante hepático evidenciou rejeição celular aguda moderada, com sinais incipientes de cronicidade, com colestase morfológica moderada e discreta dilatação sinusoidal (Fig. 5,6,7), tendo sido iniciada, então, pulsoterapia com metilprednisolona.

Figura 5: Espaço-porta demonstrado ao centro. Adjacente, observam-se hepatócitos com retenção de grânulos biliares finos em seu interior, representando quadro de colestase morfológica. (H\&E, aumento de $40 \times 10)$.

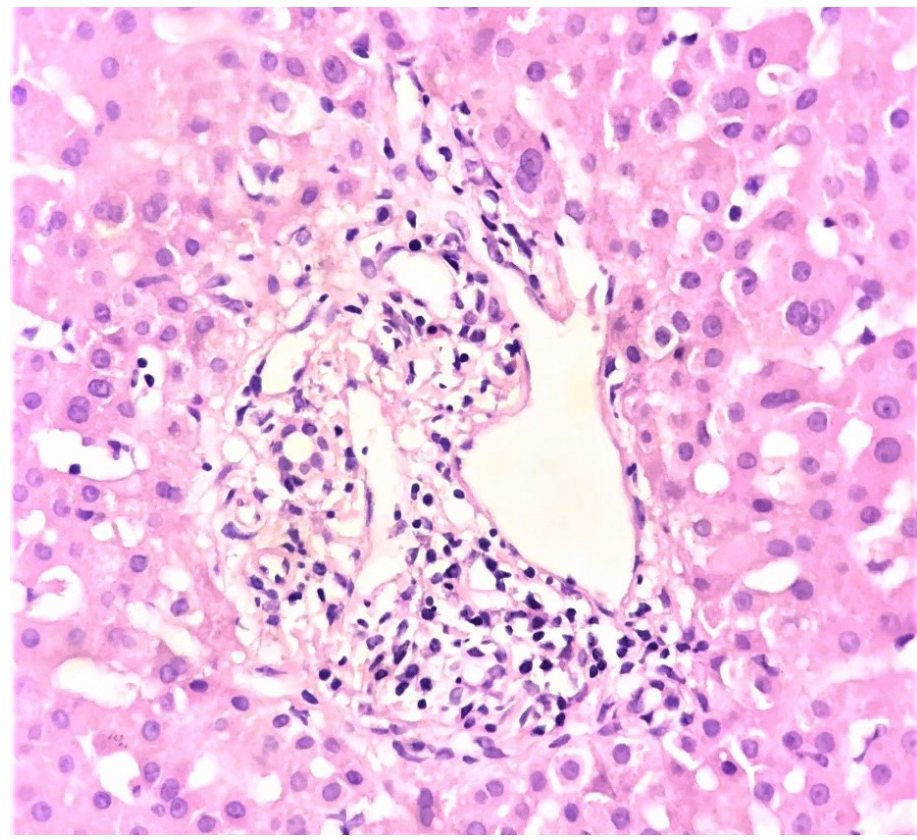

Figura 6: Espaço-porta apresentando moderado infiltrado inflamatório de predomínio linfocitário, com eosinófilos de permeio. Observam-se, também, sinais de endotelite venosa. ( $H \& E$, aumento de $40 \times 10)$.

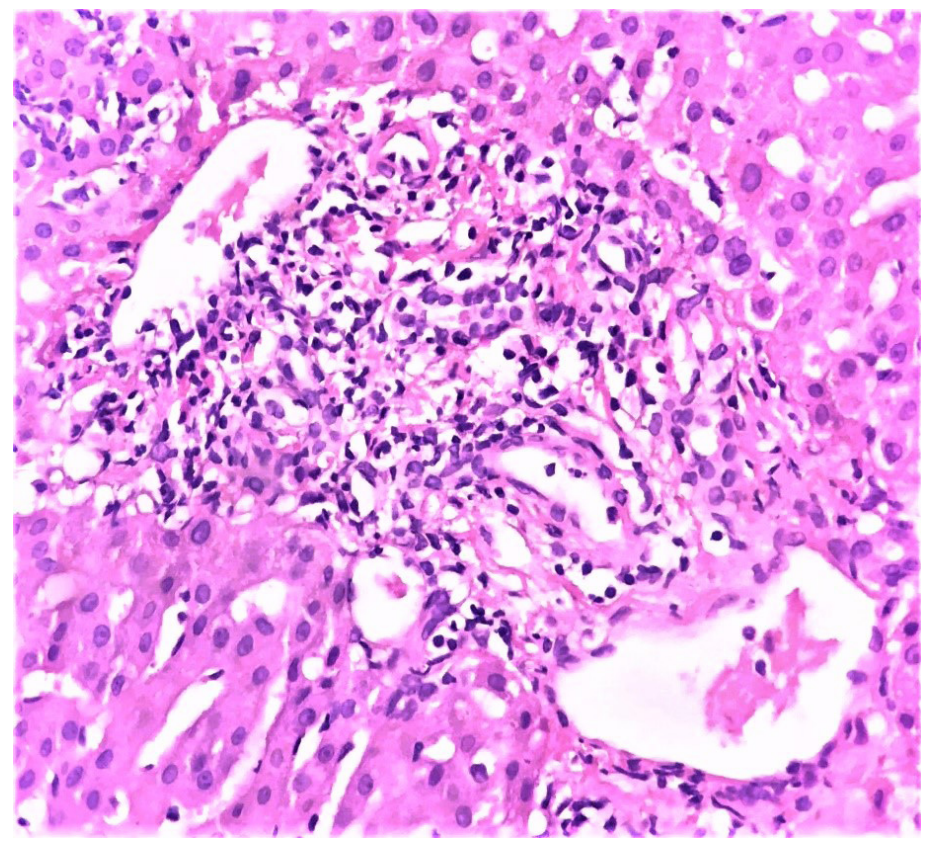

Figura 7: Espaço-porta com ductos interlobulares presentes, permeados por linfócitos. À esquerda, observa-se foco de agressão à placa limitante. (H\&E, aumento de $40 \times 10$ ).

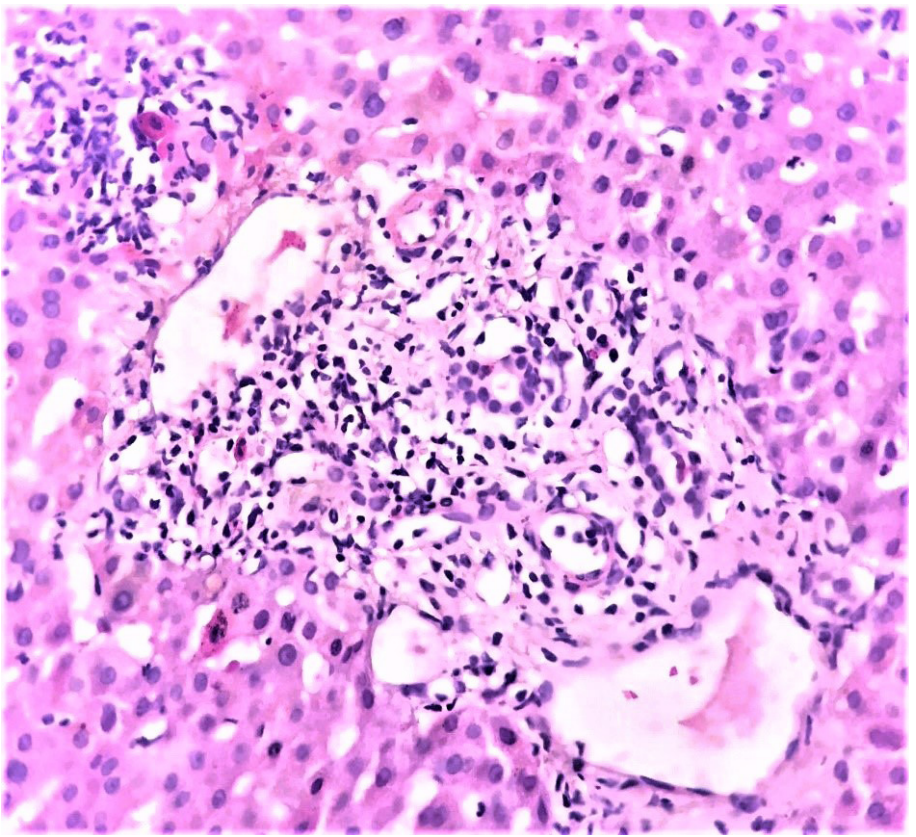

Nesse período, o paciente evoluiu com quadro confusional agudo, com rebaixamento do sensório e crise convulsiva isolada, bem como episódio de hemorragia digestiva baixa resolvido espontaneamente. O quadro neurológico resolveu-se após instituição de tratamento clínico e medidas de suporte, considerando a hipótese diagnóstica de encefalopatia hepática. 
Mariana Santos Leite Pessoa, Marina Seixas Studart e Neves, Ivelise Regina Canuto Brasil, Gabriela Maia Coelho, José Telmo Valença Júnior, Jorge Luis Bezerra Holanda

O paciente recebeu alta hospitalar dois meses e quatro dias após a internação, em considerável melhora dos parâmetros laboratoriais, clinicamente estável, sem queixas, tendo sido encaminhado para acompanhamento ambulatorial.

\section{CONCLUSÃO}

Os pacientes submetidos a transplante hepático ocasionalmente desenvolvem complicações como calcificações, que por sua vez podem levar à disfunção do enxerto. Em alguns casos, microcalcificações são detectadas nos fígados transplantados e atribuídas à lesão de isquemia-reperfusão. Em outros casos, porém, foi observado o desenvolvimento de calcificações macroscópicas, como no caso relatado, levando à perda de função do enxerto, podendo levar à necessidade de retransplante. Infelizmente, o mecanismo fisiopatológico das calcificações é pouco conhecido.

Este relato de caso demonstrou achados de imagem inespecíficos, mas que podem estar associados a sequelas de isquemia e/ou rejeição, no contexto clínico do paciente avaliado.

Precisamos de mais estudos que possibilitem maior descrição e associação dos achados de imagem demonstrados no caso supracitado à isquemia ou rejeição do enxerto hepático, bem como para compreender os mecanismos de calcificação do enxerto hepático, visto que a detecção precoce de complicações pós-transplante ajudará a diminuir as taxas de morbidade e permitir a recuperação do enxerto em casos selecionados.

\begin{abstract}
Imaging exams are widely used in the evaluation of complications after liver transplantation, however, reports in the literature of graft calcifications are rare and nonspecific, and may refer more frequently to injury-reperfusion damage, ischemia or even rejection. We report a case of a male patient, forty-eight years old, diabetic and hypertensive, hospitalized for liver transplantation due to cryptogenic cirrhosis and schistosomiasis. About twenty days after the transplant, he presented changes in clinical and biochemical parameters with elevation of canalicular enzymes and hyperbilirubinemia, notably direct bilirubin, with imaging exams showing pericapsular dystrophic hepatic calcifications, as well as hepatic artery stenosis, with angioplasty performed without placement of stent. Biopsy of the liver graft showed acute cell rejection. Further studies are needed with a greater description and characterization of post-transplant liver calcifications, as well as an understanding of the mechanisms that provide these calcifications, insofar as the early detection of post-transplant complications will help to reduce morbidity rates and allow graft recovery in selected cases.
\end{abstract}

Keywords: Liver Transplantation, Diagnostic Imaging, Graft Rejection, Ischemia. 


\section{REFERÊNCIAS}

1. Singh AK, Nachiappan AC, Verma HA, Uppot RN, Blake MA, Saini S et al. Postoperative Imaging in Liver Transplantation: What Radiologists Should Know. Radiographics 2010 Mar-Apr;30:339-51.

2. Dupuy D, Costello P, Lewis D, Jenkins R. Abdominal CT findings after liver transplantation in 66 patients. AJR Am J Roentgenol. 1991 Jun;156(6):1167-70.

3. Registro Brasileiro de Transplantes. Associação Brasileira de Transplante de Órgãos (ABTO). Ano XXV Num. 4 Jan/ Dez de 2019.

4. Jeng KS, Huang CC, Lin CK, Lin CC, Chen KH. Graft calcification caused by a torsion of the hepatic vein after a living-related donor liver transplantation. Ann Hepatol. 2017 Jan-Feb;16(1):164-8.
5. Tzimas GN, Afshar M, Chevet E, Emadali A, Vali H, Metrakos PP. Graft calcifications and dysfunction following liver transplantation. BMC Surg. 2004;4:9.

6. Kalantari F, Miao D, Emadali A, Tzimas GN, Goltzman D, Vali $\mathrm{H}$ et al. Cellular and molecular mechanisms of abnormal calcification following ischemia-reperfusion injury in human liver transplantation. Mod Pathol. 2007 Mar;20(3):357-66.

7. Talmon GA, Wisecarver JL. Hepatocellular calcification in severe ischemia-reperfusion injury in a liver allograft. Ultrastruct Pathol. 2010 Dec;34(6):362-5. doi: 10.3109/01913123.2010.506254.

8. Munoz SJ, Nagelberg SB, Green PJ, Angstadt JD, Yang $\mathrm{SL}$, Jarrell BE, et al. Ectopic soft tissue calcium deposition following liver transplantation. Hepatology. 1988 MayJun;8(3):476-83. 